Research Article

\title{
The Mathematical Modeling, Simulation, and Practice of a Multipoint Synchronous Lifting Control Case Study for Bridges
}

\author{
Jianjun Wang $\mathbb{D}^{1,2}$ Jingyi Zhao $\mathbb{D}^{1}{ }^{1}$ and Wenlei $\mathrm{Li}^{1}$ \\ ${ }^{1}$ College of Mechanical Engineering, Yanshan University, Qinhuangdao 066004, China \\ ${ }^{2}$ College of Mechanical Engineering, Anhui Technical College of Mechanical and Electrical Engineering, Wuhu 241000, China
}

Correspondence should be addressed to Jingyi Zhao; zjy@ysu.edu.cn

Received 12 June 2019; Revised 26 August 2019; Accepted 12 September 2019; Published 29 November 2019

Academic Editor: José Domingo Álvarez

Copyright (c) 2019 Jianjun Wang et al. This is an open access article distributed under the Creative Commons Attribution License, which permits unrestricted use, distribution, and reproduction in any medium, provided the original work is properly cited.

\begin{abstract}
In the combined transportation of multiple girder transport vehicles, the lifting of multiple hydraulic cylinders must ensure a certain synchronization accuracy, otherwise the bridge structure will be damaged, and even serious construction accidents will occur. The synchronous lifting of a large prefabricated bridge is studied. According to the requirements of synchronous lifting of the bridge, the appropriate control strategy is selected and the hydraulic system of synchronous lifting device is designed. The mathematical model of the synchronous lifting hydraulic system is established, and the fuzzy PID controller is applied. The simulation of the fuzzy adaptive PID control system for the synchronous lifting device is carried out by using MATLAB simulation software, and the simulation results indicate that the rationality of the control system is verified. The experimental results show that the control of the system is convenient and the synchronization accuracy is high, which can provide a reference for the synchronous lifting control.
\end{abstract}

\section{Introduction}

When the bridge is affected by load and natural environment for a long time, there will be different degrees of structural damage, which needs to be replaced when it is serious. Girder bridges are widely used in modern urban roads, and this type of bridges has a large span and a large traffic flow. Once the bridge needs to be rebuilt, it will have a huge impact on the traffic. The conventional method of replacing the bridge will take a long time, which will seriously hinder the traffic. Therefore, the new technology of rapid bridge replacement is urgently needed to reduce the impact on the traffic [1].

After entering the 21st century, SPMT (self-propelled modular transporter) is gradually being used in bridge replacement and new construction projects. It can significantly improve the work efficiency and complete the construction within a few hours. The impact of traffic will be reduced to a minimum, and the safety of construction will also be improved $[2,3]$.
In addition, the integral prefabricated bridge can be transported to the bridge site and installed, which can ensure the sufficient concrete maintenance time of the bridge deck pavement and the long-term quality of the bridge $[4,5]$. In recent years, with the increasing number of successful construction projects, the technology level of bridge transportation and lifting has been improved. But at present, there is a lack of systematic scientific theoretical basis and lack of the early improvement and argumentation process, mainly relying on many years of construction experience. This is the problem of further improvement for bridge lifting technology, which needs further in-depth study [6].

For the heavy-duty and large-scale bridges, multiple hydraulic cylinders are often required to lift the load simultaneously. If there is asynchrony in the lifting process, it will cause mechanical structure, overturning, and even major accident. Therefore, it is of great significance to study how to achieve high-precision synchronous control of multiple hydraulic cylinders [7-9]. Because of the difference of manufacturing precision, leakage, and friction resistance, 
even the hydraulic cylinders with identical structures also cannot achieve high-precision synchronization [10]. Therefore, a suitable synchronous control strategy must be adopted to improve the control accuracy of the multiactuator hydraulic system [11]. In order to ensure the safety and reliability of bridge transportation and lifting, especially in the combined transportation, the multicylinder lifting system requires high synchronization accuracy.

In this paper, the synchronous lifting system of a large bridge under the SPMT method is studied. According to the technical requirements of the synchronous lifting, the electrohydraulic closed-loop displacement control system and the "master-slave" control scheme are designed. This paper is a successful application of bridge rebuilding. The research results can solve the problem that synchronization lifting accuracy is difficult to improve under the large load and large partial load. The popularization and application of the research results can effectively achieve the rapid and safe construction of bridge engineering. At the same time, the research results also have the guidance significance to the synchronization control of other multiple actuators.

This paper is organized as follows: the lifting system and technical requirements for synchronous lifting are analyzed in Section 2. The mathematical model of the single channel lifting system is established, and the transfer function of electrohydraulic proportional valve is obtained in Section 3. According to the multicylinder synchronous lifting scheme based on the "master-slave" control strategy, the control effects under 600 tons and 1000 tons load conditions are compared by using fuzzy PID technology and MATLAB simulation software in Section 4. The results show that the "master-slave" control strategy based on fuzzy PID is suitable for the technological requirements of bridge lifting. Finally, Section 5 carries out the synchronous lifting test, and the results show that the multiple lifting cylinders run steady and have high synchronization accuracy.

\section{Lifting System Analysis}

2.1. Lifting System Introduction. The difference between girder transport vehicle and ordinary transport vehicle is that the lifting hydraulic cylinders are installed on the platform of the girder transport vehicle. As shown in Figure 1, the integration of transporting and lifting can be realized. The lifting system is an important part of the girder transport vehicle, which is composed of the mechanical structure and hydraulic and electronic control system. It can realize all lifting tasks in the whole construction process.

In the process of bridge lifting, if the synchronization error of lifting the hydraulic cylinder exceeds the safety range, the bridge will generate additional internal stress, which will cause damage to the bridge structure [12]. At the same time, in actual construction, because of the vertical error of the hydraulic cylinder installation and other unfavorable factors, it is difficult to ensure the absolute vertical of the lifting hydraulic cylinder, which will inevitably produce part of the horizontal force in the lifting process, so the limit device and monitoring measures must be taken in the lifting process.

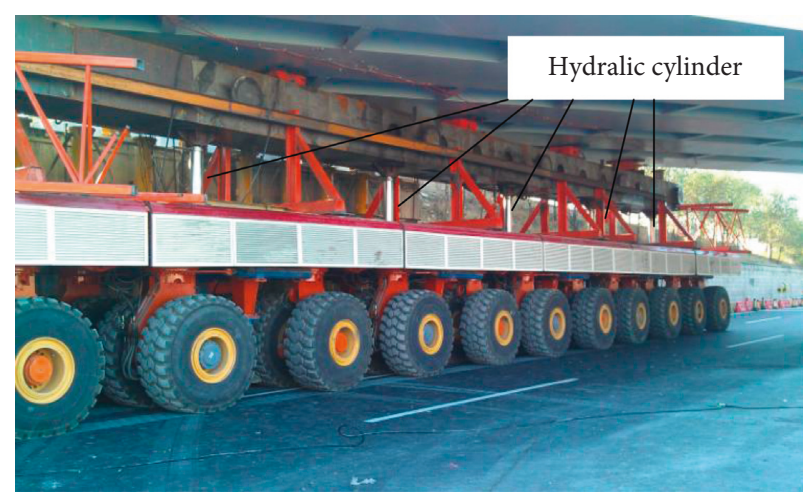

FIgURE 1: The hydraulic lifting system of a bridge transport vehicle.

In some large prefabricated bridge erection process, especially in the transportation of special-shaped bridges, the combined transportation is required. The combined transportation [13] by two vehicles is shown in Figure 2, and the combined transportation [14] by four vehicles is shown in Figure 3. At this time, the lifting system of multiple vehicles constitutes a complex group of hydraulic systems, and the synchronous lifting control of multiple points becomes particularly important.

2.2. Technical Requirements for Synchronous Lifting. The background of this paper is the actual project of lifting and removing the old bridge and erecting the new bridge. The requirement for precise control of the lifting device is high, which requires accurate control of the lifting speed and displacement and ensures that the multipoint synchronization errors in the lifting are controlled within a safe range [15]. The force analysis of the bridge is carried out by using finite element software. When the displacement deviation of less than $5 \mathrm{~mm}$ occurs during the lifting process of old bridge demolition, the bridge structure will not crack in theory and can meet the demolition standard. When the new bridge is erected as a whole, because the new bridge is an integral steel structure, the allowable deformation range is large, and it can also meet the installation and construction standards.

Therefore, the displacement deviation is required to be controlled within $5 \mathrm{~mm}$, which puts forward high technical requirements for the design of electrohydraulic control system. Once the displacement deviation reaches or exceeds the allowable value, the control system will immediately alarm and close the hydraulic system to ensure the safety of the bridge body, then analyze and find out the reasons, and finally continue lifting operation after all problems are solved.

\section{Mathematical Model of Single Channel Lifting System}

3.1. Displacement Control Principle of Hydraulic Cylinder. The composition of the displacement control system of the hydraulic cylinder is designed as shown in Figure 4. It is a closed-loop electrohydraulic proportional position control system. The set displacement signal is transmitted to the 


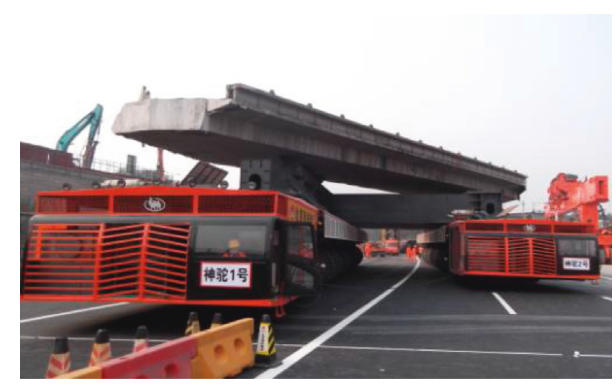

FIGURE 2: The combined transportation of the special-shaped bridge by two vehicles.

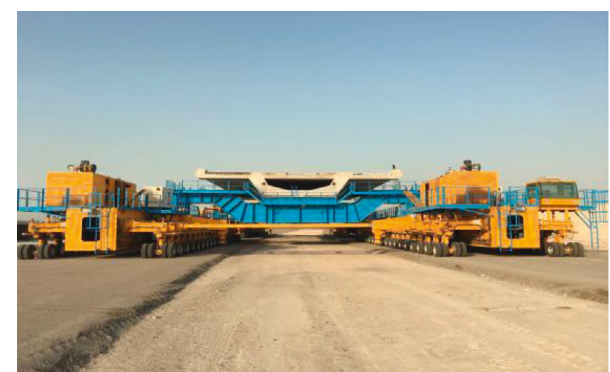

FIGURE 3: The combined transportation of the large prefabricated bridge by four vehicles.

proportional amplifier through the controller, and then the proportional directional valve is controlled through the amplifier to control the flow to the hydraulic cylinder. The displacement sensor detects the displacement of the hydraulic cylinder and compares it with the set displacement. The displacement deviation can be reduced by the controller.

3.2. Mathematical Model of Valve-Controlled Cylinder. The symmetrical valve-controlled asymmetrical hydraulic cylinder system is adopted in the multicylinder synchronous lifting hydraulic system. In order to make the model of the valve-controlled asymmetrical cylinder simple and intuitive, the ideal state assumption is made as follows when establishing the mathematical model of the system [16]:

(1) The valve is an ideal zero-opening four-way slide valve, and it is symmetrical

(2) The internal and external leakage of the hydraulic cylinder is an ideal laminar flow, and the compressibility of the oil can be neglected

(3) The valve has the ideal responsiveness; that is, the flow change can occur instantaneously with the displacement of the spool and the pressure change of the valve

(4) The supply oil pressure $P_{s}$ is constant, and the return oil pressure $P_{0}$ is zero

(5) The pressure loss and the dynamic characteristics of the pipeline are neglected

The valve-controlled cylinder system diagram is shown in Figure 5.
The load pressure can be defined according to the external load of the hydraulic cylinder. When the piston is extended, the expression of the load pressure can be obtained as follows:

$$
p_{L}=\frac{F_{L}}{A_{1}}=\frac{p_{1} A_{1}-p_{2} A_{2}}{A_{1}}=p_{1}-n p_{2},
$$

where $p_{L}$ is the external load pressure of the hydraulic cylinder, $p_{1}$ is the pressure of left cavity in the hydraulic cylinder, $p_{2}$ is the pressure of right cavity in the hydraulic cylinder, $A_{1}$ is the area of left cavity in the hydraulic cylinder, and $A_{2}$ is the area of right cavity in the hydraulic cylinder.

When the spool of the valve moves to the right, the piston rod of the hydraulic cylinder extends; according to assumptions (1) and (4), the flow equation of the left and right chambers of the hydraulic cylinder can be obtained as follows:

$$
\begin{aligned}
& q_{1}=C_{d} W x_{v} \sqrt{\frac{2}{\rho}\left(p_{s}-p_{1}\right)} \approx A_{1} \frac{\mathrm{d} y}{\mathrm{~d} t}, \\
& q_{2}=C_{d} W x_{v} \sqrt{\frac{2}{\rho} p_{2}} \approx A_{2} \frac{\mathrm{d} y}{\mathrm{~d} t},
\end{aligned}
$$

where $q_{1}$ is the flow of left cavity in the hydraulic cylinder, $q_{2}$ is the flow of right cavity in the hydraulic cylinder, $P_{s}$ is the supply pressure, $C_{d}$ is the flow coefficient of the proportional valve, $x_{v}$ is the spool displacement, $W$ is the throttle area gradient, and $\rho$ is the hydraulic oil density.

From equations (2) and (3), the following conclusions can be obtained:

$$
\frac{q_{2}}{q_{1}}=\sqrt{\frac{p_{2}}{p_{s}-p_{1}}} \approx \frac{A_{2}}{A_{1}}=n .
$$

Through equations (1)-(4), the following equations can be obtained:

$$
\begin{aligned}
& p_{1}=\frac{n^{3} p_{s}+p_{L}}{1+n^{3}}, \\
& p_{2}=\frac{n^{2}\left(p_{s}-p_{L}\right)}{1+n^{3}} .
\end{aligned}
$$

The output power of the hydraulic cylinder is as follows:

$$
P_{\text {out }}=p_{1} q_{1}-p_{2} q_{2} \text {. }
$$

Generally, the following equation is valid under ideal conditions:

$$
P_{\text {out }}=P_{L}=p_{L} q_{L}
$$

So the load flow can be defined in the following form:

$$
q_{L}=q_{1} .
$$

The pipeline between proportional valve and hydraulic cylinder is short and thick, so the pressure loss in the pipeline can be neglected. It is considered that the pressure is equal everywhere in the hydraulic cylinder, the bulk modulus of elasticity and oil temperature are constant, and the 


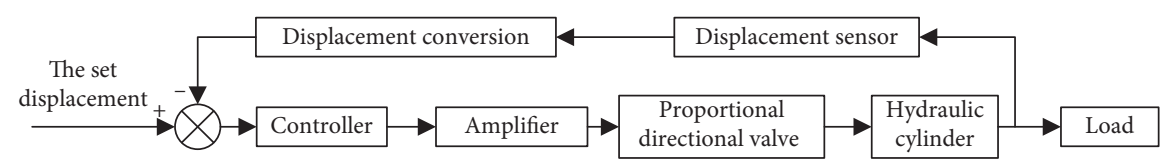

FIGURE 4: The displacement control principle of the single hydraulic cylinder.

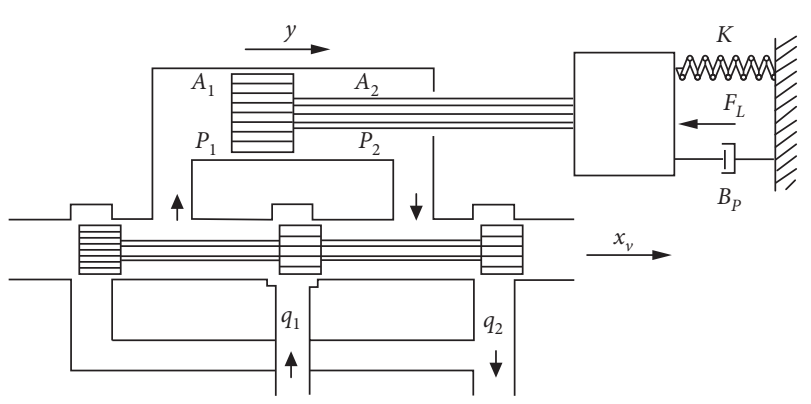

FIGURE 5: Valve-controlled cylinder system diagram.

flow state of internal and external leakage is considered as laminar flow. And according to assumptions (2) and (5), the following equation can be obtained:

$$
\begin{aligned}
& q_{1}=C_{i p}\left(p_{1}-p_{2}\right)+C_{e p} p_{1}+\frac{V_{1}}{\beta_{e}} \frac{\mathrm{d} p_{1}}{\mathrm{~d} t}+\frac{\mathrm{d} V_{1}}{\mathrm{~d} t}, \\
& q_{2}=C_{i p}\left(p_{1}-p_{2}\right)-C_{e p} p_{2}-\frac{V_{2}}{\beta_{e}} \frac{\mathrm{d} p_{2}}{\mathrm{~d} t}-\frac{\mathrm{d} V_{2}}{\mathrm{~d} t},
\end{aligned}
$$

where $C_{i p}$ is the internal leakage coefficient of the hydraulic cylinder, $C_{e p}$ is the external leakage coefficient of the hydraulic cylinder, $\beta_{e}$ is the effective bulk modulus of elasticity, $V_{1}$ is the effective volume of the left chamber of the hydraulic cylinder, and $V_{2}$ is the effective volume of the right chamber of the hydraulic cylinder.

The effective volume in equations (10) and (11) can be written as follows:

$$
\begin{aligned}
& V_{1}=V_{10}+A_{1} y, \\
& V_{2}=V_{20}+A_{2} y,
\end{aligned}
$$

where $V_{10}$ is the initial volume of the left chamber of the hydraulic cylinder, $V_{20}$ is the initial volume of the right chamber of the hydraulic cylinder, and $y$ is the output displacement of the hydraulic cylinder piston rod.

Through equations (10)-(13), the following equations can be obtained:

$$
\begin{aligned}
& q_{1}=C_{i p}\left(p_{1}-p_{2}\right)+C_{e p} p_{1}+\frac{V_{1}}{\beta_{e}} \frac{\mathrm{d} p_{1}}{\mathrm{~d} t}+A_{1} \frac{\mathrm{d} y}{\mathrm{~d} t}, \\
& q_{2}=C_{i p}\left(p_{1}-p_{2}\right)-C_{e p} p_{2}-\frac{V_{2}}{\beta_{e}} \frac{\mathrm{d} p_{2}}{\mathrm{~d} t}+A_{2} \frac{\mathrm{d} y}{\mathrm{~d} t} .
\end{aligned}
$$

Through equations (5), (6), (14), and (15), the flow equation of the hydraulic cylinder is obtained as follows:

$$
q_{L}=q_{1}=C_{i e} p_{L}+C_{f} p_{s}+\frac{V_{t}}{4 \beta_{e}} \frac{\mathrm{d} p_{L}}{\mathrm{~d} t}+A_{1} \frac{\mathrm{d} y}{\mathrm{~d} t},
$$

where $C_{i e}$ is the equivalent leakage coefficient, $C_{f}$ is the additional leakage coefficient, and $V_{t}$ is the equivalent total volume. And $C_{i e}, C_{f}$, and $V_{t}$ are defined as follows:

$$
\begin{aligned}
& C_{i e}=\frac{\left[C_{i p}\left(1+n^{2}\right)+C_{e p}\right]}{\left(n^{3}+1\right)}, \\
& C_{f}=n^{2} \frac{\left[\left(C_{i p}+C_{e p}\right) \cdot n-C_{i p}\right]}{\left(n^{3}+1\right)}, \\
& V_{t}=\frac{4 V_{1}}{1+n^{3}} .
\end{aligned}
$$

When the piston of the hydraulic cylinder is in the middle position, the compressibility of the oil is the most remarkable, the natural frequency of the power component is the minimum, the damping is the minimum, and the stability is the worst. Therefore, except for the middle position, all other locations are safe. The selected analysis position is the piston in the middle of the hydraulic cylinder.

When the spool of the directional valve moves to the right, the flow equation of the directional valve is as follows:

$$
q_{L}=K_{q} x_{v}-K_{c} p_{L}
$$

where $K_{q}$ is the flow gain and $K_{c}$ is the flow-pressure coefficient.

When the piston rod extends outward $(y>0)$, the balance equation between the output force and the load force of the hydraulic cylinder is as follows:

$$
p_{1} A_{1}-p_{2} A_{2}=p_{L} A_{1}=m_{t} \frac{\mathrm{d}^{2} y}{\mathrm{~d} t}+B_{P} \frac{\mathrm{d} y}{\mathrm{~d} t}+K y+F_{L},
$$

where $K$ is the equivalent stiffness of load spring, $m_{t}$ is the total mass of piston and load converted to piston, and $B_{P}$ is the viscous damping coefficient between piston and load.

Equations (16), (20), and (19) are transformed by Laplace transform, and the results are obtained as follows:

$$
\begin{aligned}
Q_{L}(s) & =K_{q} X_{V}(s)-K_{c} P_{L}(s), \\
Q_{L}(s) & =C_{i e} P_{L}(s)+A_{1} s Y(s)+\frac{V_{t}}{4 \beta_{e}} s P_{L}(s), \\
A_{1} P_{L}(s) & =m_{t} s^{2} Y(s)+B_{P} s Y(s)+K Y(s)+F_{L}(s) .
\end{aligned}
$$

By eliminating the intermediate variables from equation (20)-(22), the relation equation between the output displacement of the hydraulic cylinder, the displacement of the directional valve spool, and the external load force can be obtained as follows: 


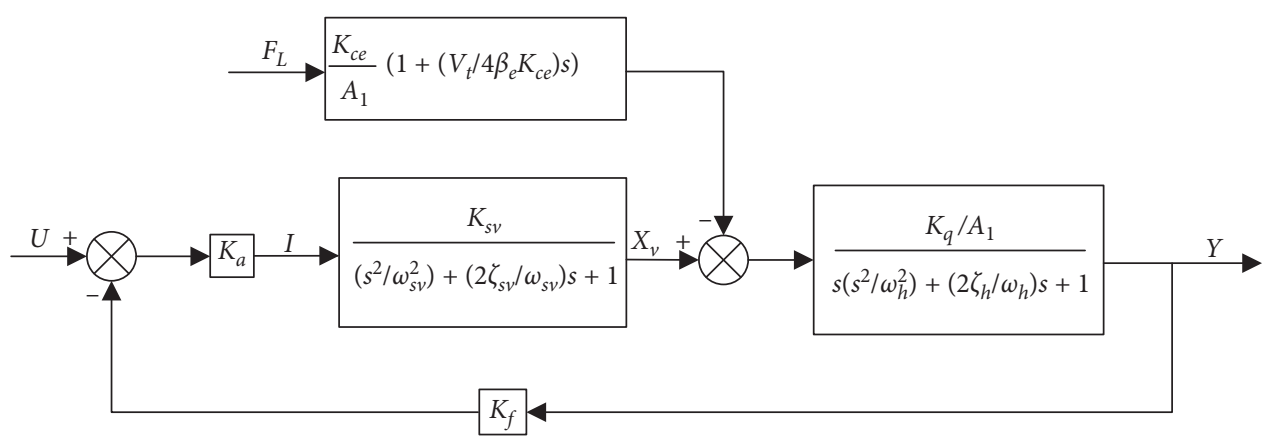

FIGURE 6: The block diagram of transfer function of the lifting system.

$$
Y(s)=\frac{\left(K_{q} / A_{1}\right) X_{V}-K_{c e} / A_{1}^{2}\left(1+\left(V_{t} / 4 \beta_{e} K_{c e}\right) s\right) F_{L}(s)}{\left(m_{t} V_{t} / 4 \beta_{e} A_{1}^{2}\right) s^{3}+\left(\left(m_{t} K_{c e} / A_{1}^{2}\right)+\left(B_{P} V_{t} / 4 \beta_{e} A_{1}^{2}\right)\right) s^{2}+\left(1+\left(B_{P} K_{c e} / A_{1}^{2}\right)+\left(K V_{t} / 4 \beta_{e} A_{1}^{2}\right)\right) s+\left(K K_{c e} / A_{1}^{2}\right)},
$$

where $K_{c e}=K_{c}+C_{i e}$ is the total flow-pressure coefficient.

In this system, the elastic load is very small and can be neglected, that is, $K=0$. Generally, viscous damping coefficient $B_{P}$ is small enough to be negligible. Then equation (23) can be simplified as follows:

$$
Y(s)=\frac{\left(K_{q} / A_{1}\right) X_{V}-\left(K_{c e} / A_{1}^{2}\right)\left(1+\left(V_{t} / 4 \beta_{e} K_{c e}\right) s\right) F_{L}(s)}{s\left(\left(s^{2} / \omega_{h}^{2}\right)+2 \zeta_{h} / \omega_{h} s+1\right)},
$$

where $\omega_{h}$ is the hydraulic natural frequency, $\zeta_{h}$ is the hydraulic damping ratio, and $\omega_{h}$ and $\zeta_{h}$ are defined as follows:

$$
\begin{aligned}
& \omega_{h}=\sqrt{\frac{4 \beta_{e} A_{1}^{2}}{V_{t} m_{t}}}, \\
& \zeta_{h}=\frac{K_{c e}}{A_{1}} \sqrt{\frac{\beta_{e} m_{t}}{V_{t}}} .
\end{aligned}
$$

3.3. Transfer Function of Electrohydraulic Proportional Valve. In engineering, the proportional reversing valve can generally be regarded as a second-order oscillation element, so the transfer function of the electrohydraulic proportional valve can be written as follows:

$$
G_{1}(S)=\frac{X_{V}(s)}{I(s)}=\frac{K_{s v}}{\left(s^{2} / \omega_{s v}^{2}\right)+\left(2 \zeta_{s v} / \omega_{s v}\right) s+1},
$$

where $X_{V}$ is the spool displacement, $I$ is the input current, $K_{s v}$ is the gain of spool displacement to input current, $\omega_{s v}$ is the natural frequency of the proportional directional valve, and $\zeta_{s v}$ is the hydraulic damping ratio of the proportional directional valve.

The proportional amplifier can be approximated as a proportional element because of its high dynamic response and turning frequency. The transfer function of the proportional amplifier can be expressed as follows:

$$
K_{a}(s)=\frac{I(s)}{U(s)},
$$

where $K_{a}$ is the proportional amplifier gain and $U$ is the proportional amplifier input voltage.

The function of the displacement sensor is to convert the position signal of the piston rod of the input hydraulic cylinder into the corresponding voltage signal, so it can be simplified into a proportional element, and the transfer function is as follows:

$$
K_{f}(s)=\frac{U_{f}(s)}{Y(s)},
$$

where $K_{f}$ is the gain of the displacement sensor, $U_{f}$ is the feedback voltage signal, and $Y$ is the displacement of the hydraulic cylinder.

According to equations (24) and (26)-(28), the block diagram of transfer function of the electrohydraulic proportional valve-controlled hydraulic cylinder system can be obtained as shown in Figure 6.

\section{Control Mode and Simulation of Synchronous Lifting System}

4.1. Simulation Analysis of Fuzzy-PID Control for Lifting System. The fuzzy PID control is developed on the basis of ordinary PID control. It is the product of the combination of fuzzy theory and PID control. At the same time, it is also a control method often used in industry. The main difference between the control method and the traditional control is that the three parameters of the conventional PID are fixed and unchanged, while the fuzzy PID can change $K_{p}, K_{i}$, and $K_{d}$ according to the change of the error signal so as to improve the control effect. The Simulink simulation model of single channel lifting system fuzzy PID control is designed as shown in Figure 7.

The step response simulation analysis of the system is carried out, the load is set to 100 tons, and the simulation results are shown in Figure 8. Compared with the conventional PID control, the step response curve of the system is more stable, the overshoot is obviously reduced and the anti-interference ability is strong after using the fuzzy PID control. The lifting process is relatively stable, which can 


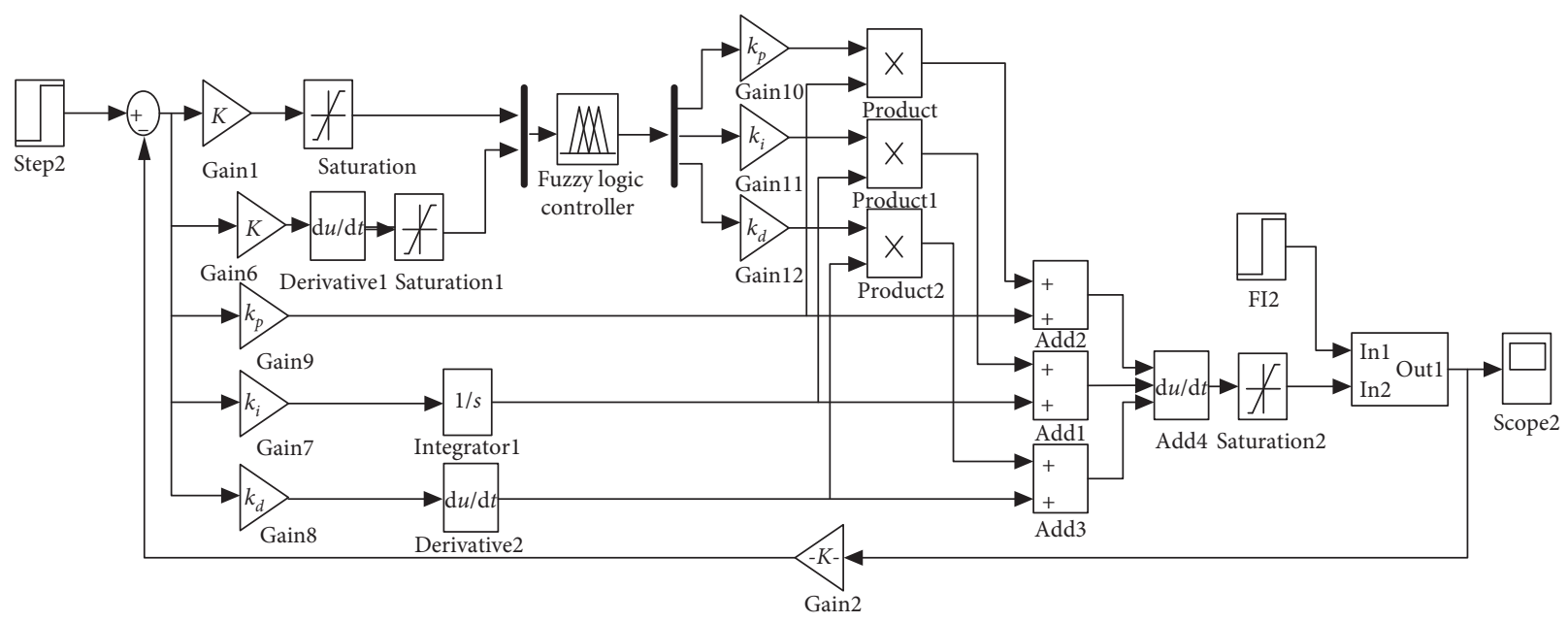

FIgURE 7: The simulation model of fuzzy PID control of the single channel lifting system.

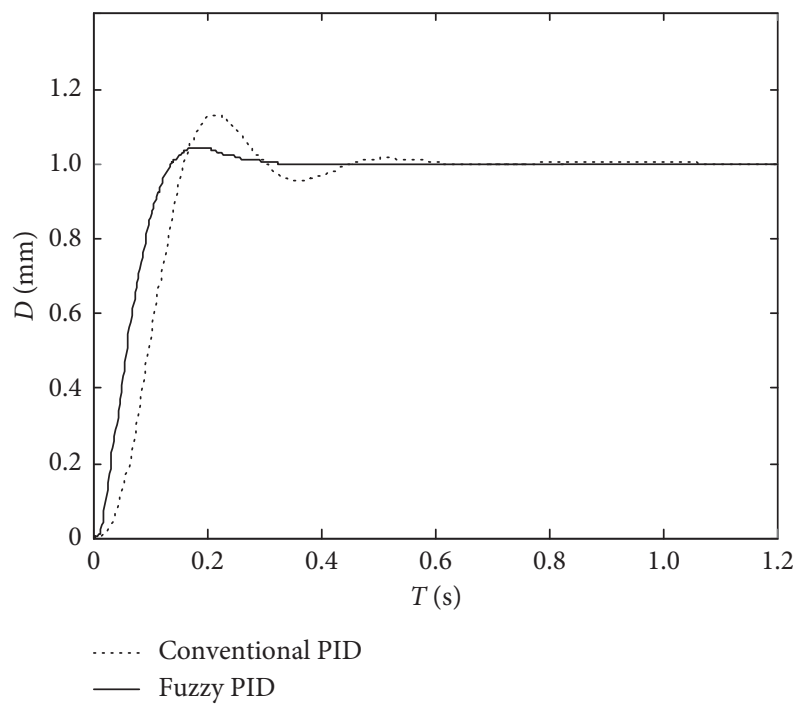

FIGURE 8: The step response curve of two type control modes.

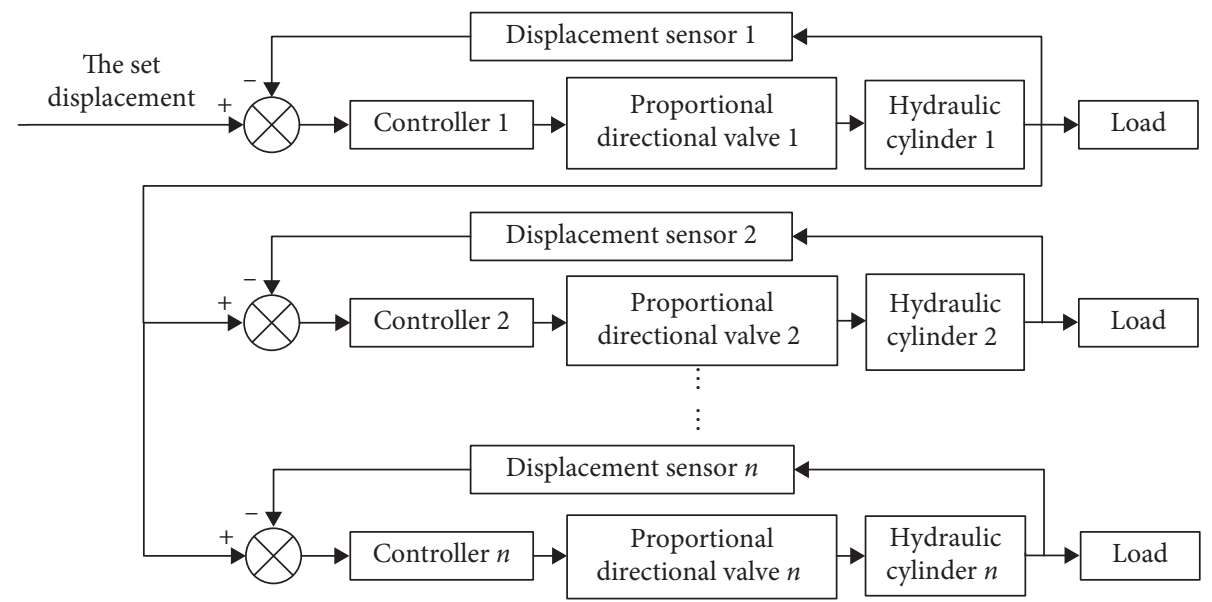

FIGURE 9: The "master-slave" control scheme. 


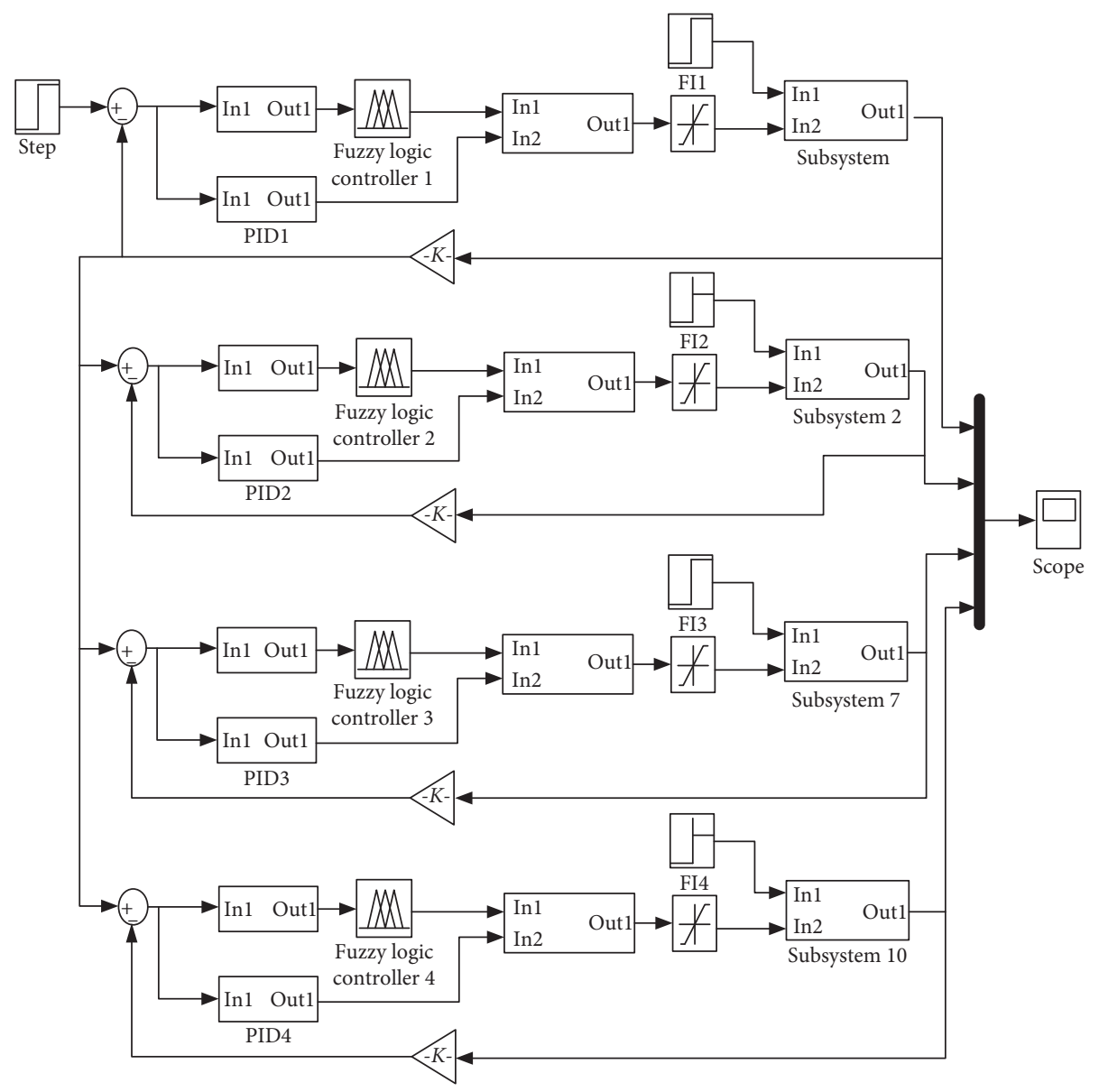

FIGURE 10: The simulation model of "master-slave" synchronization control.

ensure the safety of the bridge lifting. At the same time, it can be seen that the response time is faster and the steady-state error is smaller from Figure 8. In summary, compared with conventional control, the fuzzy PID control has better performance and is more suitable for the bridge lifting.

4.2. Synchronized Lifting Control Scheme. There are many ways of hydraulic synchronization control. Open-loop control uses synchronous loop, and closed-loop control uses "the equal mode" and "master-slave mode" and so on. Closed-loop control can often obtain higher control accuracy $[17,18]$. The lifting system of multivehicle-combined operation belongs to multigroup cylinder system, and synchronization is more difficult [19]. In order to obtain better synchronization accuracy and dynamic response, a combination of "master-slave" control strategy and fuzzyPID control strategy is adopted after referring to a large number of relevant literature and similar research experience [20]. The "master-slave" control scheme of the lifting system is shown in Figure 9.

4.3. Simulation and Analysis of Synchronous Lifting Control. Considering the bridge as a platform supported by four points, a four-point synchronous lifting system is designed [21]. "Master-slave" synchronization control uses displacement output signal of Point 1 as control input signal of

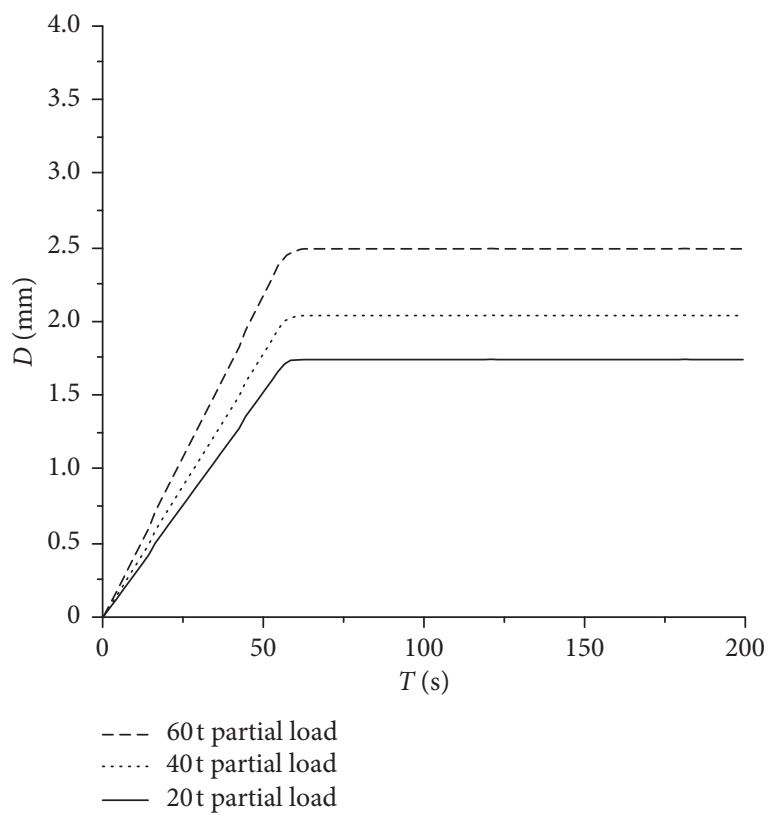

Figure 11: The synchronization error curves of $600 \mathrm{t}$ load.

Points 2, 3, and 4. At the same time, each point returns its output to form closed-loop control. The simulation model is established as shown in Figure 10. 


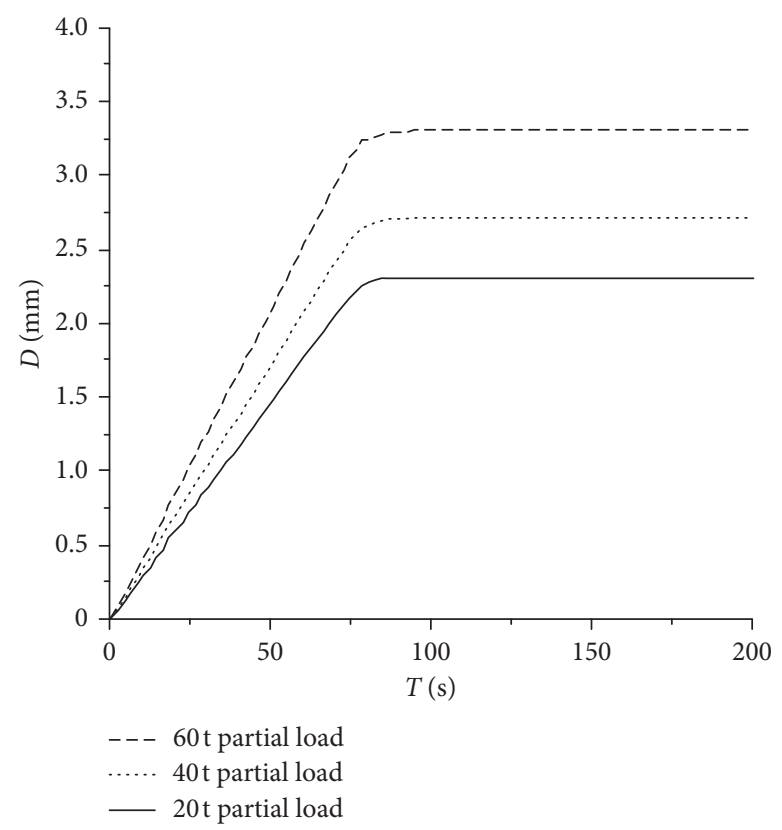

Figure 12: The synchronization error curves of $1000 \mathrm{t}$ load.

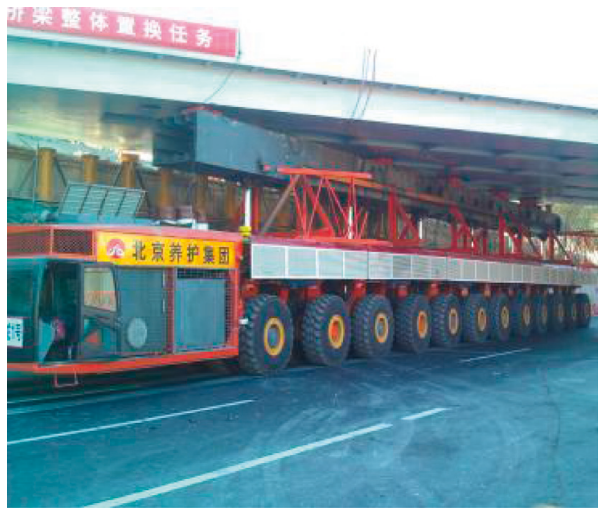

(a)

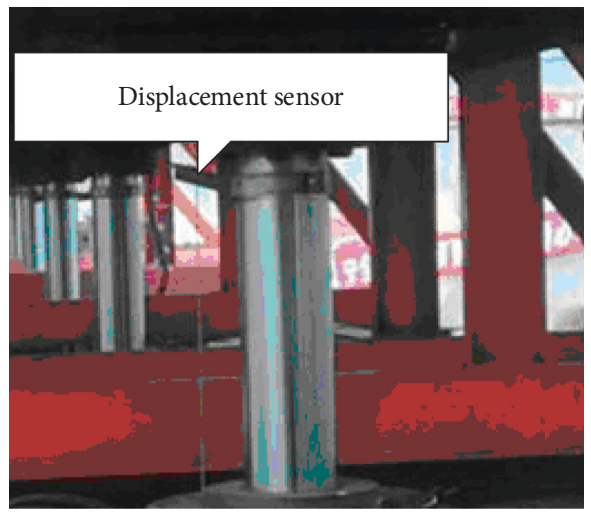

(b)

FIGURE 13: The synchronous lifting experiment.

In the simulation, the total loads are set to $600 \mathrm{t}$ and $1000 \mathrm{t}$, the error curves of synchronous lifting displacement using "master-slave" synchronous control strategy are shown in Figures 11 and 12. When the initial partial loads are $20 \mathrm{t}, 40 \mathrm{t}$, and $60 \mathrm{t}$, it can be seen that the maximum synchronous errors of the lifting system are $1.7 \mathrm{~mm}, 2.0 \mathrm{~mm}, 2.5 \mathrm{~mm}$ and $2.3 \mathrm{~mm}$, $2.7 \mathrm{~mm}, 3.3 \mathrm{~mm}$, respectively. It can be seen that it fully meets the technical requirements of bridge lifting.

\section{Debugging Experiment of Synchronous Lifting System}

For this synchronous lifting system, the new control strategy is studied by using mathematical modeling and simulation software, some control parameters of the controller are determined, and the advancement of the control strategy is verified. However, the simulation model cannot fully reflect the actual operation. It is necessary to conduct field test and debugging to further determine whether the effect of the scheme is ideal.

The mathematical modeling and the simulation can provide reference for the design. After the design scheme is determined and completed and the assembly and manufacture of the whole vehicle is completed, the debugging experiment of the synchronous lifting is carried out to verify the rationality of the design. After the inspection, the lifting experiment is carried out, as shown in Figure 13.

The real-time displacement signals of each hydraulic cylinder can be obtained in the experiment. After the experiment, the synchronization error curves under partial load and no partial load are obtained as shown in Figure 14. It can be seen that the displacement deviation is less than $5 \mathrm{~mm}$, and it can meet the requirement of the bridge synchronous lifting. 


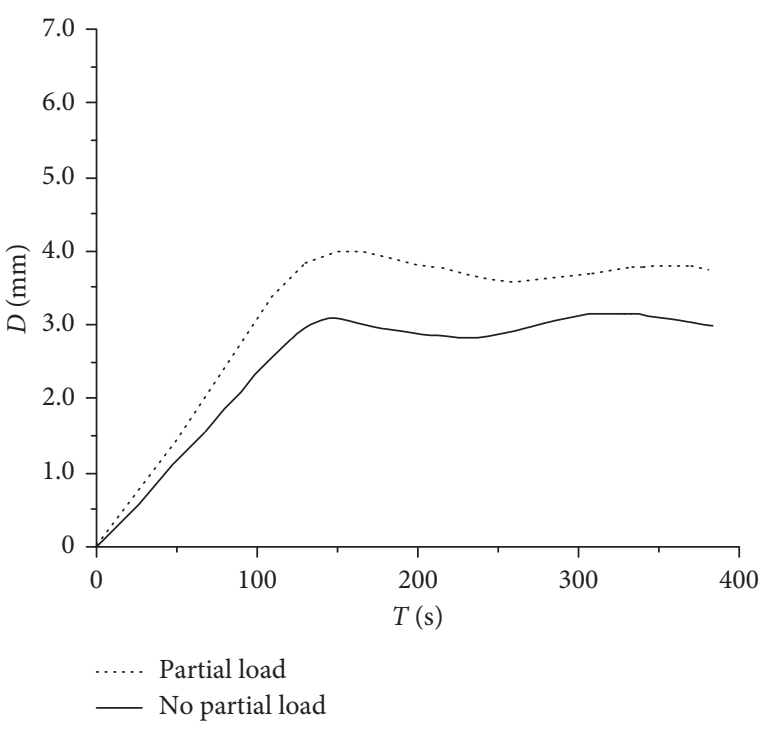

Figure 14: The test synchronization error curves.

\section{Results}

Aiming at multicylinder synchronous lifting of the large prefabricated bridge, a single-channel mathematical model of the lifting system is established, and the transfer function between displacement of the hydraulic cylinder and proportional reversing valve is obtained. The "masterslave" synchronization control strategy is selected and designed. The synchronization effect is verified by using the MATLAB software. The fuzzy PID control is applied into the model, and the parameters in the simulation model are adjusted to get the best effects. It is verified that the fuzzy PID control and the "master-slave" control strategy is very effective from the simulation results. And the test results show that the high synchronous accuracy under the large load and large unbalance load can be obtained after the application of this strategy in multicylinder synchronous lifting.

\section{Data Availability}

All data generated or analyzed during this study are included within this manuscript. If necessary, other relevant data can be made available from the corresponding author via mail upon request.

\section{Conflicts of Interest}

The authors declare that there are no conflicts of interest regarding the publication of this paper.

\section{Acknowledgments}

This work was supported by the National Natural Science Foundation of China (51675461) and the Scientific Research Project Foundation of Anhui Education Department (KJ2019A1161).

\section{References}

[1] F. Yan, "Discussion on synchronized lifting of highway bridges under continuous traffic," Traffic World, vol. 6, pp. 171-173, 2011.

[2] M. Ralls, B. Tang, and H. Russell, "Self-propelled modular transporters for bridge movements in Europe and the United States," Transportation Research Record: Journal of the Transportation Research Board, vol. 11, pp. 17-22, 2005.

[3] H. G. Russell, M. L. Ralls, and B. M. Tang, "Prefabricated bridge elements and systems in Japan and Europe," Transportation Research Record: Journal of the Transportation Research Board, vol. 1928, no. 1, pp. 102-109, 2005.

[4] Federal Highway Administration, Manual on Use of SelfPropelled Modular Transporters to Remove and Replace Bridges, Federal Highway Administration, Washington, DC, USA, 2007.

[5] E. S. Rosvall, M. W. Halling, and R. Lindsey, "Induced stresses from lifting and moving highway bridges with self-propelled modular transporters," Transportation Research Record: Journal of the Transportation Research Board, vol. 2200, no. 1, pp. 17-25, 2010.

[6] Y. Zhao, L. I. Jianjun, and Y. U. Shan, "Successful application of SPMT method in Beijing Changping West Island bridge reconstruction project," Municipal Engineering Technology, vol. 30, no. 2, pp. 3-5, 2012.

[7] Q. Han, H. Zhang, and J. Liu, "Nonlinear dynamics of controlled synchronizations of manipulator system," Mathematical Problems in Engineering, vol. 2014, Article ID 691464, 9 pages, 2014.

[8] D. Su, G. Han, J. Yu, and H. Shi, "Design and application of hydraulic synchronization control system," Journal of Shenyang University of Technology, vol. 27, no. 4, pp. 364-367, 2005.

[9] M. S. A. D. Ali, N. R. Babu, and K. Varghese, "Collision free path planning of cooperative crane manipulators using genetic algorithm," Journal of Computing in Civil Engineering, vol. 19, no. 2, pp. 182-193, 2005.

[10] L.-w. Yang and Z.-p. Jia, "Study on the hydraulic synchronization system used on the lift platform of the port embarkation bridge," Chinese Hydraulics \& Pneumatics, vol. 8, pp. 44-46, 2012.

[11] H. L. Gao and Y. Sang, "Discuss on synchronization control and its typical application," Hydraulics Pneumatics \& Seals, vol. 32, no. 5, pp. 1-7, 2012.

[12] J.-y. Zhao, L. Yang, S.-f. Rong, Y. Guo, and W.-l. Li, "Reliability analysis of hydraulic lifting system on parallel bridgetransporting vehicle," Chinese Hydraulics \& Pneumatics, vol. 4, pp. 8-13, 2012.

[13] H. Yao, Y.-g. Lou, and X.-y. Xie, "Influence analysis of bridge synchronous lifting on bridge structure," China Municipal Engineering, vol. 1, pp. 28-30, 2017.

[14] Y. Huang, "Bridge erection construction and complete equipment design of Kuwait bay bridge," Construction Machinery and Equipment, vol. 46, no. 1, pp. 51-58, 2015.

[15] Q. Yang, "Construction technology study on complete replacement of rubber support of bridge," Technology of Highway and Transport, vol. 3, pp. 126-130, 2007.

[16] B. Qiang and B. Liu, "Modeling and simulation of electrohydraulic proportional valve-controlled hydraulic cylinder system," Hoisting and Conveying Machinery, vol. 32, no. 11, pp. 35-39, 2011. 
[17] F. D. Grosu, A. Bîrzu, A. Lazar, and I. Grosu, "Coupling systems for a new type of phase synchronization," Mathematical Problems in Engineering, vol. 2016, p. 7, 2016.

[18] G. Hu, L. Liu, G. Gong, and H. Yang, "Simulation and experimental analyses of synchronization control for shield thrust system," China Mechanical Engineering, vol. 19, no. 10, pp. 1197-1201, 2008

[19] Y. Chen, X. Wang, G. Pan, and Y. Han, "Coupling leveling controller design of electro-hydraulic multi-axis synchronous loading for hydraulic support test rig," Journal of China Coal Society, vol. 36, no. 10, pp. 1762-1767, 2011.

[20] J. Zhao, F. Cheng, R. Guo, and J. Dai, "Research on electrohydraulic synchronization driving control for self-propelled transporter suspension lifting," China Mechanical Engineering, vol. 25, no. 7, pp. 972-978, 2014.

[21] J. Zhao, Y. Yang, S. Kang, Z. Wang, and T. Liu, "Research and application of four-point support "flat chasing style" leveling strategy on self-propelled hydraulic transporter," Machine Tool \& Hydraulics, vol. 43, no. 15, pp. 57-60, 2015. 


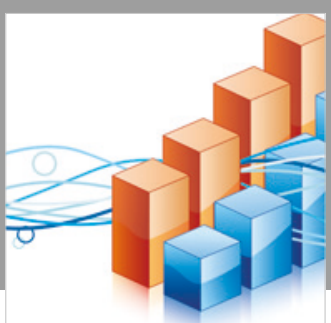

Advances in

Operations Research

\section{-n-m}
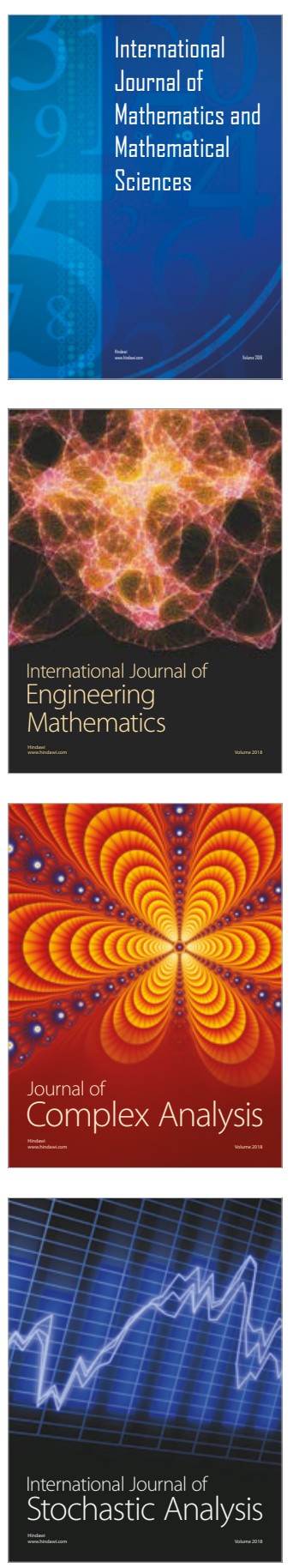
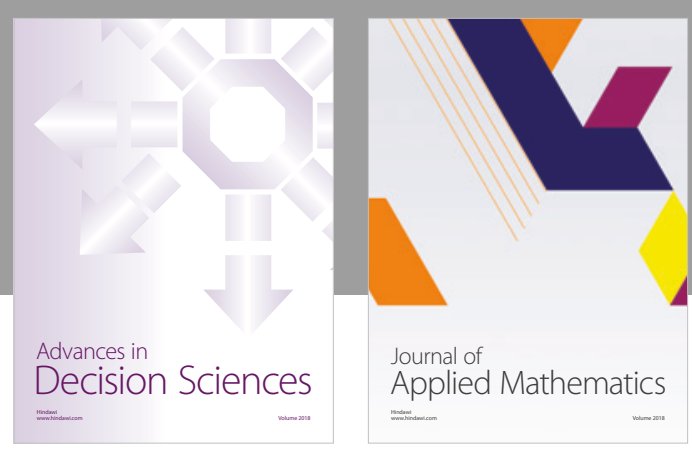

Journal of

Applied Mathematics
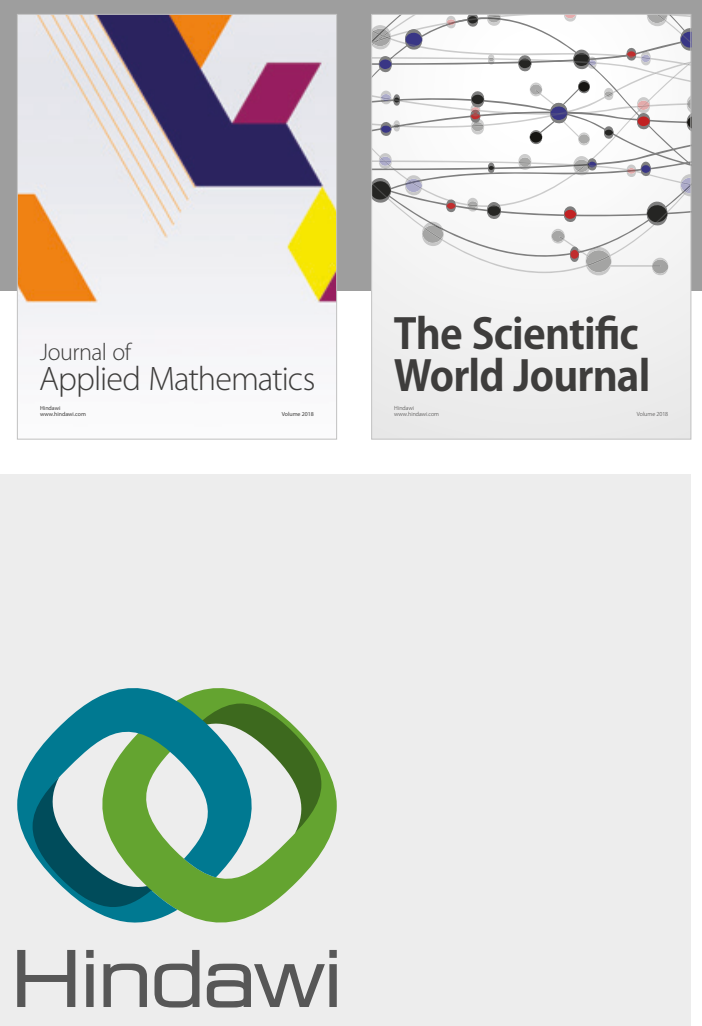

Submit your manuscripts at

www.hindawi.com

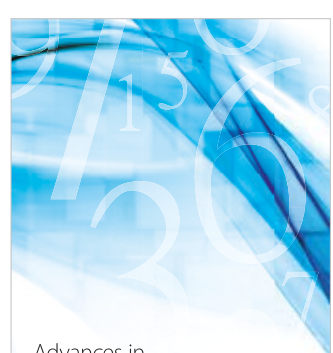

Advances in
Numerical Analysis
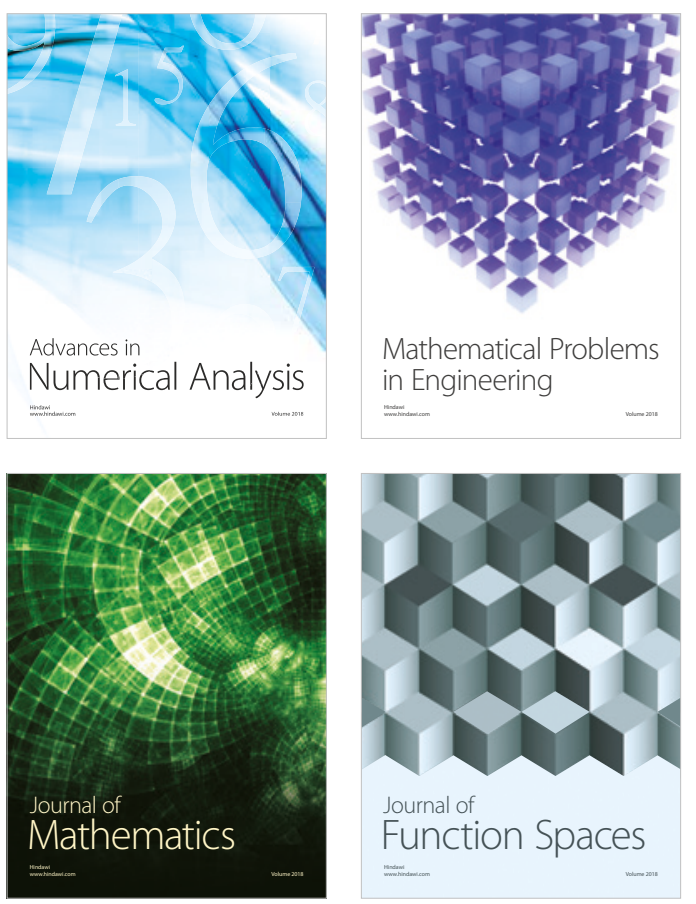

Mathematical Problems in Engineering

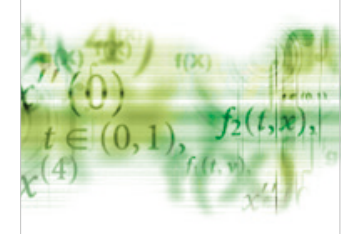

International Journal of

Differential Equations

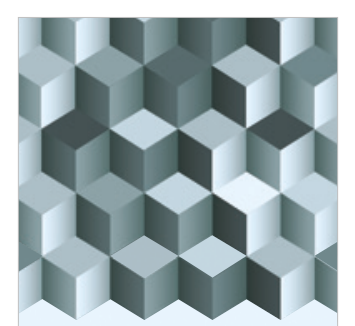

Journal of

Function Spaces

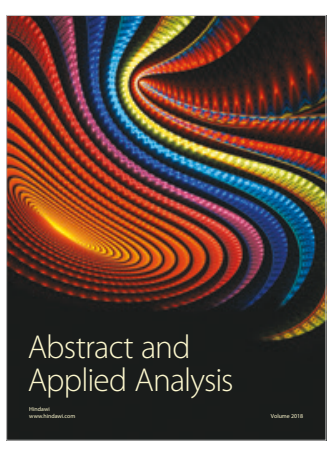

The Scientific

World Journal

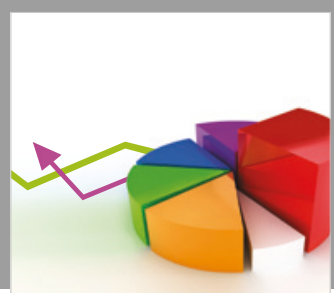

Journal of

Probability and Statistics
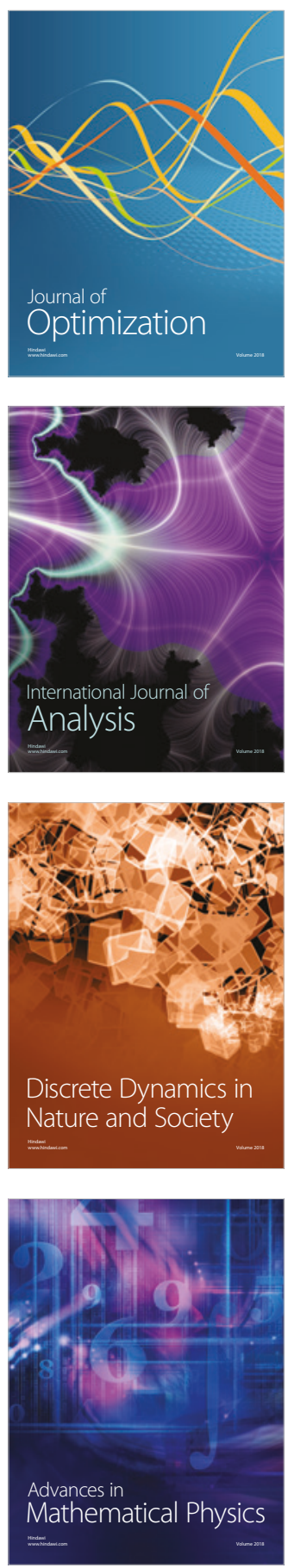